\title{
Association of years to parent's sporadic onset and risk factors with neural integrity and Alzheimer biomarkers
}

\author{
Eider M. Arenaza-Urquijo, PhD, Gemma Salvadó, MSc, Gregory Operto, PhD, Carolina Minguillón, PhD, \\ Gonzalo Sánchez-Benavides, PhD, Marta Crous-Bou, PhD, Oriol Grau-Rivera, MD, PhD, Aleix Sala-Vila, PhD, \\ Carles Falcón, PhD, Marc Suárez-Calvet, MD, PhD, Henrik Zetterberg, MD, PhD, Kaj Blennow, MD, PhD, \\ Juan Domingo Gispert, PhD, and José Luis Molinuevo, MD, PhD, for the ALFA Study
}

Neurology ${ }^{\circledR}$ 2020;95:e2065-e2074. doi:10.1212/WNL.0000000000010527

\author{
Correspondence \\ Dr. Arenaza-Urquijo \\ earenaza@ \\ barcelonabeta.org
}

\section{MORE ONLINE}

$\rightarrow$ Class of Evidence

Criteria for rating

therapeutic and diagnostic

studies

NPub.org/coe

\section{Methods}

This observational study included 290 cognitively unimpaired (CU) participants with a family history $(\mathrm{FH})$ of clinically diagnosed sporadic $\mathrm{AD}$ (age 49-73 years) from the Alzheimer's and Families (ALFA) study. $\left[{ }^{18} \mathrm{~F}\right]$ flutemetamol-PET standardized uptake value ratios, CSF $\beta$-amy$\operatorname{loid}_{42 / 40}$ ratio, and phosphorylated tau were used as $\mathrm{AD}$ biomarkers. Hippocampal volumes and CSF total tau were used as neural injury biomarkers. Mental and vascular health proxies were calculated. In multiple regression models, we assessed the effect of proximity to parental AAO and its interaction with age on $\mathrm{AD}$ and neural injury biomarkers. Then, we evaluated the effects of $\mathrm{FH}$ load (number of parents affected), sex, APOE $\varepsilon 4$, education, and vascular and mental health.

\section{Results}

Proximity to parental AAO was associated with $\beta$-amyloid, but not with neural injury biomarkers, and interacted with sex and age, showing that women and older participants had increased $\beta$-amyloid. FH load and APOE $\varepsilon 4$ showed independent contributions to $\beta$-amyloid load. Education and vascular and mental health proxies were not associated with $\mathrm{AD}$ biomarkers. However, lower mental health proxies were associated with decreased hippocampal volumes with age.

\section{Conclusion}

The identification of the earliest biomarker changes and modifiable factors to be targeted in early interventions is crucial for $\mathrm{AD}$ prevention. Proximity to parental $\mathrm{AAO}$ may offer a timeline for detection of incipient $\beta$-amyloid changes in women. In risk-enriched middle-aged cohorts, mental health may be a target for early interventions.

\section{ClinicalTrials.gov identifier}

NCT02485730.

\section{Classification of evidence}

This study provides Class II evidence that in $\mathrm{CU}$ adults with $\mathrm{FH}$ of sporadic $\mathrm{AD}$, proximity to parental AAO was associated with $\beta$-amyloid but not with neural injury biomarkers.

\footnotetext{
From the Barcelonaßeta Brain Research Center (E.M.A.-U., G.S., G.O., C.M., G.S.-B., M.C.-B., O.G.-R., A.S.-V, C.F., M.S.-C., J.D.G., J.L.M.), Pasqual Maragall Foundation; IMIM (Hospital del Mar Medical Research Institute) (E.M.A.-U., G.S., G.O., C.M., G.S.-B., M.C.-B., O.G.-R., A.S.-V, C.F., M.S.-C., J.D.G., J.L.M.), Barcelona; Centro de Investigación Biomédica en Red de Fragilidad y Envejecimiento Saludable (E.M.A.-U., G.S., G.O., C.M., G.S.-B., M.C.-B., O.G.-R., M.S.-C., J.L.M.), Madrid, Spain; Department of Epidemiology (M.C.-B.), Harvard TH Chan School of Public Health, Boston, MA; Servei de Neurologia (O.G.-R., M.S.-C.), Hospital del Mar, Barcelona; Investigación Biomédica en Red Bioingeniería, Biomateriales y Nanomedicina (C.F., J.D.G.), Madrid, Spain; Clinical Neurochemistry Laboratory (H.Z., K.B.), Sahlgrenska University Hospital, Mölndal; Department of Psychiatry and Neurochemistry (H.Z., K.B.), Institute of Neuroscience and Physiology, The Sahlgrenska Academy at the University of Gothenburg, Mölndal, Sweden; Department of Neurodegenerative Disease (H.Z.), UCL Institute of Neurology, Queen Square; UK Dementia Research Institute at UCL (H.Z.), London; and Universitat Pompeu Fabra (J.D.G., J.L.M.), Barcelona, Spain.

Go to Neurology.org/N for full disclosures. Funding information and disclosures deemed relevant by the authors, if any, are provided at the end of the article.

ALFA Study coinvestigators are listed in the appendix 2 at the end of the article.
} 


\section{Glossary}

AAO = age at onset $\mathbf{A} \beta=\beta$-amyloid $\mathbf{A D}=$ Alzheimer disease; ALFA+ = Alzheimer's and Families; $\mathbf{C U}=$ cognitively unimpaired; FH = family history; HADS = Hospital Anxiety and Depression Scale; SUVR = standardized uptake value ratio; TIV $=$ total intracranial volume.

The optimal time window to prevent Alzheimer disease (AD) dementia is probably before substantial neuronal loss occurs when individuals are still asymptomatic. Recent evidence suggests a very early window for therapeutic treatment in participants showing subthreshold amyloid increases. ${ }^{1,2}$ Indeed, even incipient increases of $\mathrm{AD}$ pathology have deleterious effects on brain and cognition. ${ }^{1,2}$ Identification of individuals showing the earliest detectable biomarker changes is thus crucial for clinical trials to succeed.

Midlife is a critical period of divergence between normal and pathologic aging. ${ }^{3}$ While the prevalence of $\mathrm{AD}$ pathologic change in cognitively unimpaired $(\mathrm{CU})$ adults during midlife is low (10\%), the estimates are 3 to 4 times higher in middleaged CU adults with a genetic predisposition. ${ }^{4}$ Moreover, middle-aged $\mathrm{CU}$ adults with family history of sporadic $\mathrm{AD}$ start showing $\mathrm{AD}$-related pathologic changes during midlife. ${ }^{5}$ A recent study showed that proximity to parental age at onset (AAO) may help capture incipient amyloid changes during midlife in $\mathrm{CU}$ participants with a family history (FH) of sporadic $\mathrm{AD} .^{6}$

Furthermore, middle-aged adults with $\mathrm{FH}$ of sporadic $\mathrm{AD}$ are at increased risk for developing dementia and thus represent a candidate population for lifestyle interventions. Recent research suggests that risk and protective factors for neural injury and amyloid are different. ${ }^{7}$ Yet, few studies have focused on understanding the role of risk and protective factors on imaging and CSF biomarkers in midlife. ${ }^{8,9}$ Because the presence of both neural injury and $\mathrm{AD}$ pathologies best predicts cognitive impairment, understanding the role that risk and protective factors play in increasing resistance to $\mathrm{AD}$ pathologies (amyloid and tau) and brain resilience (brain structure and function) in risk-enriched populations is fundamental. ${ }^{10}$

The present study focuses on CU middle-aged adults with $\mathrm{FH}$ of clinically diagnosed $\mathrm{AD}$ with the following objectives: (1) to evaluate the association between proximity to $\mathrm{AAO}$ and $\mathrm{AD}$ pathologies (measured with CSF and PET), (2) to test the association between AAO and biomarkers of neuronal injury (hippocampal volume and CSF total tau), and (3) to provide a comprehensive evaluation of the role of nonmodifiable (sex, FH load [number of affected parents], APOE $\varepsilon 4)^{4,11,12}$ and modifiable (years of education, mental and vascular health) factors. ${ }^{13-17}$ We hypothesized that proximity to parental AAO will be associated with $\mathrm{AD}$ pathologic changes and to a lesser extent with neural injury markers. Furthermore, we hypothesized that modifiable and nonmodifiable factors are associated differently with $\mathrm{AD}$ and neural injury biomarkers.

\section{Methods}

\section{Participants}

Two hundred ninety-one participants of the Alzheimer's and Families (ALFA+) study were included in this cross-sectional investigation (table 1). ALFA+ is a nested longitudinal study of the ALFA parent cohort. In brief, the ALFA cohort was established as a research platform to characterize preclinical $\mathrm{AD}$ and is composed of 2,743 cognitively unimpaired individuals between 45 and 75 years of age with increased risk for $\mathrm{AD}{ }^{18}$ In the nested ALFA+ study, participants underwent advanced protocols of MRI, amyloid PET imaging with $\left[{ }^{18} \mathrm{~F}\right]$ flutemetamol, and assessment of CSF core $\mathrm{AD}$ biomarkers. The participants included here represented the first consecutive cases with $\mathrm{FH}$ of clinically diagnosed $\mathrm{AD}$ and available biomarker data. As described below, from the initial sample with self-reported FH $(\mathrm{n}=332), 290$ had available hippocampal volumes. From these, 276 had available CSF biomarker data, and 260 had amyloid-PET data.

Table 1 Demographics of the study sample and descriptive statistics of the main variables of the study

\begin{tabular}{|c|c|c|}
\hline & $\begin{array}{l}\text { Mean } \\
(\text { SD)/n (\%) }\end{array}$ & Range \\
\hline Age, y & $60.82(4.80)$ & $49-73$ \\
\hline Education, y & $13.50(3.54)$ & $6-20$ \\
\hline Female, n (\%) & $182(63.0)$ & - \\
\hline APOE\& 4 carriers, $\mathrm{n}(\%)$ & $136(47)$ & - \\
\hline Proximity to parental AAO, y & $-10.39(7.18)$ & $-26.64-15.90$ \\
\hline $\begin{array}{l}\text { FH load ( } 2 \text { parents affected), } n \\
(\%)\end{array}$ & $19(6.6)$ & - \\
\hline Amyloid positivity (VR), ${ }^{a}$ (\%) & 15.4 & - \\
\hline Flutemetamol-PET SUVR ${ }^{a}$ & $1.02(0.15)$ & $0.80-1.67$ \\
\hline$A \beta_{42 / 40}$ ratio, $^{b} \mathrm{pg} / \mathrm{mL}$ & $0.76(0.20)$ & $0.02-0.14$ \\
\hline Phosphorylated tau, ${ }^{b} \mathrm{pg} / \mathrm{mL}$ & $16.30(6.84)$ & $7.90-46.50$ \\
\hline Hippocampal volumes, ${ }^{\mathrm{C}} \mathrm{mm}^{3}$ & $\begin{array}{l}3,236.22 \\
(309.701)\end{array}$ & $2,515.29-4,290.79$ \\
\hline Total tau, ${ }^{\mathrm{b}} \mathrm{pg} / \mathrm{mL}$ & 197.13 & $79.90-469.60$ \\
\hline
\end{tabular}

Abbreviations: $A A O=$ age at symptom onset; $A \beta=\beta$-amyloid; SUVR = standardized uptake value ratio; VR = visual read.

${ }^{a} n=260$.

${ }^{\mathrm{b}} \mathrm{n}=276$.

${ }^{c} n=290$. 


\section{Standard protocol approvals, registrations, and patient consents}

The ALFA + study (ALFA-FPM-0311) was approved by the Independent Ethics Committee "Parc de Salut Mar," Barcelona, and registered at Clinicaltrials.gov (identifier: NCT02485730). All participants signed the informed consent form that had also been approved by the Independent Ethics Committee "Parc de Salut Mar," Barcelona.

\section{Family history of sporadic AD}

FH of sporadic $\mathrm{AD}$ was considered when (1) a self-report, (2) a clinical diagnosis, or (3) a retrospective diagnosis consistent with $\mathrm{AD}$ dementia existed. The majority of the cases (91\%) had, in addition to the self-report, a documented clinical diagnosis or a retrospective clinical diagnosis consistent with $\mathrm{AD}$ dementia. This is an ongoing study, and these data are updated during follow-up visits. Taking into account the age of the participants and their parents, significant changes in $\mathrm{FH}$ are not expected. FH updates will affect mainly the $\mathrm{FH}$ load variable ( 1 vs 2 parents).

\section{Proximity to parental AAO calculation}

The parental AAO corresponds to the age at which the participant observed significant cognitive decline in his/her parent (age at symptom onset). The proximity to parental $\mathrm{AAO}$ variable was calculated as the age of the participant at assessment minus the age of the parent at symptom onset. If participant had 2 parents with a history of $\mathrm{AD}$ dementia, the age of the parent with the earliest onset was used to calculate the proximity to parental AAO score.

\section{AD biomarkers and APOE genotyping}

\section{CSF biomarkers}

Fresh CSF samples were collected in 15-mL polypropylene tubes (Sarstedt catalog No. 62.554, Nümbrecht, Germany); the supernatant was divided into aliquots in 0.5 - $\mathrm{mL}$ polypropylene tubes (Sarstedt catalog No. 72.730.005) and frozen within 2 hours after lumbar puncture. Aliquots were placed into long-term storage boxes and stored at $-80^{\circ} \mathrm{C}$ until shipment on dry ice for analysis. CSF $\beta$-amyloid $(A \beta)_{42}$ and $A \beta_{40}$ were measured with the NeuroToolKit (Roche, Basel, Switzerland) on an Elecsys cobas e 411 instrument. The Elecsys phosphotau $\left({ }^{181} \mathrm{P}\right)$ and Elecsys total-tau immunoassays were used for CSF on a cobas e 601 analyzer at the Clinical Neurochemistry Laboratory, University of Gothenburg, Sweden, according to the kit manufacturer's instructions and as described in previous studies. ${ }^{19}$ The $A \beta_{42 / 40}$ ratio was used an outcome measure for CSF amyloid.

\section{Structural MRI}

The T1-weighted 3D turbo field echo sequence was acquired in a Philips (Best, the Netherlands) $3 \mathrm{~T}$ Ingenia CX scanner with a voxel size of $0.75 \times 0.75 \times 0.75 \mathrm{~mm}^{3}$, field of view of $240 \times 240 \times 180 \mathrm{~mm}^{3}$, sagittal acquisition, flip angle of $8^{\circ}$, repetition time of 9.9 milliseconds, echo time of 4.6 milliseconds, and inversion time of 900 milliseconds.

\section{Amyloid-PET}

PET imaging was conducted in a Siemens Biograph mCT (Munich, Germany), following a cranial CT scan for attenuation correction. Participants were injected with $185 \mathrm{MBq}$ (range 166.5-203.5 Mbq) of $\left[{ }^{18} \mathrm{~F}\right]$ flutemetamol, and 4 frames of 5 minutes each were acquired 90 minutes after injection. Images were reconstructed with an OSEM3D algorithm using 8 iterations and 21 subsets and with point spread function and time of flight corrections into a matrix size of $1.02 \times 1.02 \times$ $2.03 \mathrm{~mm}$.

\section{APOE genotype}

Total DNA was obtained from blood cellular fraction by proteinase $\mathrm{K}$ digestion followed by alcohol precipitation. The APOE allelic variants were obtained from allelic combinations of the rs429358 and rs7412 polymorphism.

\section{Vascular and mental health proxies}

A proxy of systemic vascular health was calculated from the number of reported vascular risk factors (hypertension, diabetes mellitus, dyslipidemia, heart failure, ischemic heart disease, atrial fibrillation). History of comorbid conditions was collected via structured interviews. Of the study sample, $41.6 \%$ reported 0 vascular comorbid conditions, $41 \%$ reported $1,13.5 \%$ reported 2 , and $3.5 \%$ reported $>3$. The most frequent was dyslipidemia $(45.5 \%, \mathrm{n}=141)$, followed by hypertension $(26.5 \%, \mathrm{n}=82)$, diabetes mellitus $(3.5 \%, \mathrm{n}=11)$, ischemic heart disease and $(0.3 \%, \mathrm{n}=1)$, and atrial fibrillation $(3.2 \%, \mathrm{n}$ $=10$ ). Given the data distribution, we created a factor with 2 levels: $0=$ no reported comorbid conditions and $1=\geq 1$ comorbid conditions.

A mental health indicator was created from the history of anxiety and depression collected via structured interviews. Of the study sample, $74.2 \%$ did not have a history of mental disorders, $19.4 \%$ had 1 disorder, and $6.5 \%$ had between 2 and 3 . History of clinical depression was reported by $22.6 \%$ $(\mathrm{n}=70)$ of participants; anxiety disorders were reported by $11.6 \%(n=36)$. Given the distribution of the data, we created a dichotomous variable: $0=$ no history of mental disorders and $1=$ history of mental disorders. The group with a history of mental disorders also showed higher levels of anxiety and depression during the visit as measured by the Hospital Anxiety and Depression Scale $\left(\mathrm{HADS}^{20}\right)(t=4.152, p=0.001)$.

\section{Imaging preprocessing and statistical analyses}

\section{MRI processing}

Hippocampal volumes and total intracranial volumes (TIVs) were calculated with FreeSurfer version 6.0. FreeSurfer segmentations and the distribution of hippocampal volumes values were visually inspected. We averaged right and left hippocampal volumes and adjusted them from TIV by calculating the residual from a linear regression (hippocampal volume vs intracranial volume) among the participants included in the study. Adjusted hippocampal volumes reflect the 
deviation in participants' hippocampal volumes from what is expected given their TIV. ${ }^{21}$

\section{Flutemetamol-PET}

Images were preprocessed with SPM12. In brief, average PET images were coregistered to the corresponding MRI scans and normalized to Montreal Neurological Institute space. We calculated the standardized uptake value ratio (SUVR) in Montreal Neurological Institute space, from the standard target regions (bilateral frontal and parietotemporal areas), using the whole cerebellum as reference region (see elsewhere ${ }^{22}$ for details). Furthermore, visual assessments were performed by a trained clinician. Participants were classified as amyloid positive $(\mathrm{A}+)$ or negative $(\mathrm{A}-)$. These data were included to describe the characteristics of the study sample and for supplemental analyses.

\section{Statistical models}

The characteristics of the sample are described with mean and SD for continuous variables and count and percentage for categorical variables.

We performed 2 sets of complementary multiple regression analyses with $\mathrm{AD}$ ( $\beta$-amyloid as measured by CSF $\mathrm{A} \beta_{42 / 40}$ ratio and PET and phosphorylated tau) or neural injury biomarkers (total tau and hippocampal volumes) as outcome (dependent) measurements. Following Tukey criterion for outlier detection, 1 participant was excluded from the analyses using phosphorylated tau and total tau as dependent variable. The statistical analyses were performed with IBM SPSS software (Armonk, NY).

In the first set of analyses, the measures of interest were the main effect of proximity to parental AAO and the 2-way interactions between proximity to parental AAO, age, sex, and years of education on $\mathrm{AD}$ and neural injury biomarkers. In a first step, the models included age, sex, and years of education. In a second step, the interaction terms were included in the model. Finally, we tested whether the effects of proximity to parental AAO were still significant when APOE $\varepsilon 4$ status and $\mathrm{FH}$ load (1 or 2 parents affected) were introduced into the model.

In the second set of analyses, we assessed whether mental and vascular health modified the significant effects of proximity to parental $\mathrm{AAO}$ and age and of $\mathrm{AD}$ and neural injury biomarkers.

\section{Classification of evidence}

This observational study provides Class II evidence that in $\mathrm{CU}$ late-middle-aged people with $\mathrm{FH}$ of clinically diagnosed sporadic $\mathrm{AD}$, proximity to parental $\mathrm{AAO}$ was associated with $\mathrm{A} \beta$ but not with neural injury biomarkers.

\section{Data availability}

Data that support the findings of this study are available on reasonable request from the ALFA Study Investigators.

\section{Results}

The study sample was within an average of -10.39 years before parental AAO, ranging from -26.64 to 15.9 years. Thus, $8.3 \%$ $(n=24)$ of the sample surpassed the parental AAO. This group was at an average of 4.15 years above (from 0.13 to 15.9 years).

Proximity to parental AAO and age showed a moderate positive association $(\mathrm{r}=0.45, p<0.001)$. According to visual assessments, $15.4 \%$ of the study participants were A+. Amyloidpositive participants were older $(A+: 63.87 \pm 4.31$ years, $A-$ : $60.20 \pm 4.60$ years, $t=4.68, p<0.001)$ and were closer to the parental AAO (A+: $-6.97 \pm 7.90$ years, $A-:-11.08 \pm 6.92$ years, $t=3.37, p=0.001)$. The percentage of $A+$ participants increased stepwise ( -15 years: $10.9 \%$, +5 years: $33.3 \%$, table e1, 10.5061 / dryad.280gb5mn1).

\section{Associations between proximity to parental AAO and biomarkers of AD pathologies}

In $\mathrm{AD}$ biomarker models, those considering amyloid as a dependent variable showed significant associations with proximity to parental AAO, while those considering phosphorylated tau did not.

With flutemetamol-PET SUVRs as a dependent variable, the model including only main effects showed a significant effect of age $(\beta=0.003, p<0.001)$ and a marginal effect of proximity to parental AAO $(\beta=0.001, p=0.069)$. Sex and years of education were not significant $(\beta=0.008, p=0.28$, $\beta=-0.001, p=0.16$ ).

When 2-way interactions were considered, proximity to parental AAO showed a significant interaction with age on flutemetamol-PET SUVRs. The interaction was such that the association of proximity to parental AAO with increased flutemetamol-PET SUVRs was driven by participants in late midlife (figure 1A). Sex also showed a significant interaction with proximity to parental AAO (figure $1 \mathrm{~B}$ ). The interaction was such that the association between proximity to parental AAO and amyloid-PET was stronger in women. Finally, years of education did not show a significant interaction. The statistical results are presented in table 2.

In follow-up analyses, when APOE\&4 status and FH load (1 vs 2 parents affected) were entered in the amyloid-PET model, the interaction between proximity to parental AAO and age remained significant $(\beta=0.001, p=0.003$, figure $1 C)$. Furthermore, both APOE\&4 status $(\beta=0.040, p=0.018)$ and $\mathrm{FH}$ load ( $\beta=0.08, p=0.029$ ) showed significant main effects on flutemetamol-PET SUVRs, but they did not interact with proximity to parental AAO.

In the $A \beta_{42 / 40}$ ratio model, when only main effects were considered, both age and proximity to parental AAO showed borderline effects $(\beta=-0.557, p=0.047$; and $\beta=-0.344, p=$ $0.068)$. Years of education and sex were not significant $(\beta=$ $0.023, p=0.946$; and $\beta=-0.021, p=739$ ). 
A

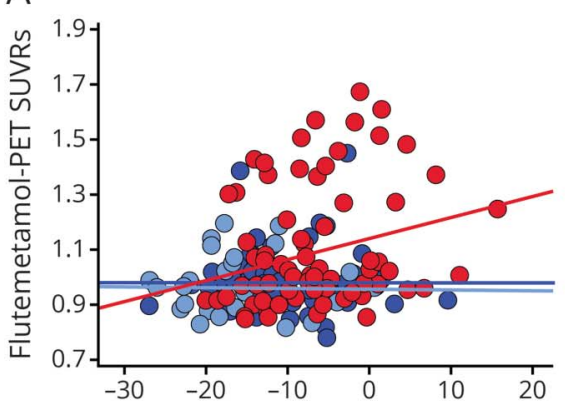

C

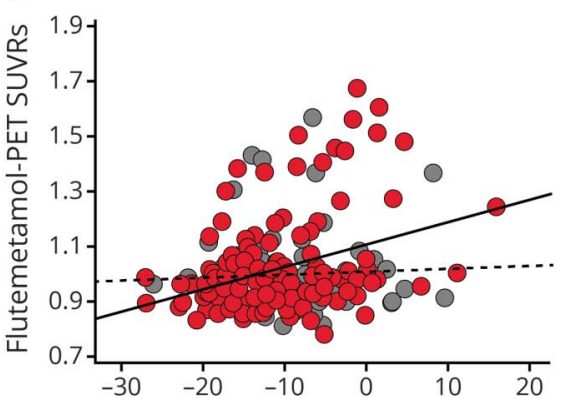

$\mathrm{E}$

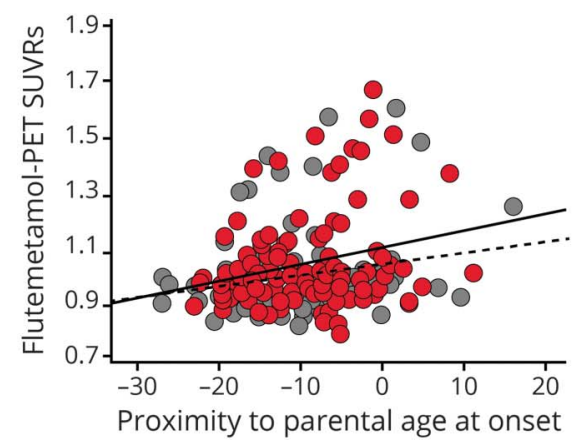

$\mathrm{B}$

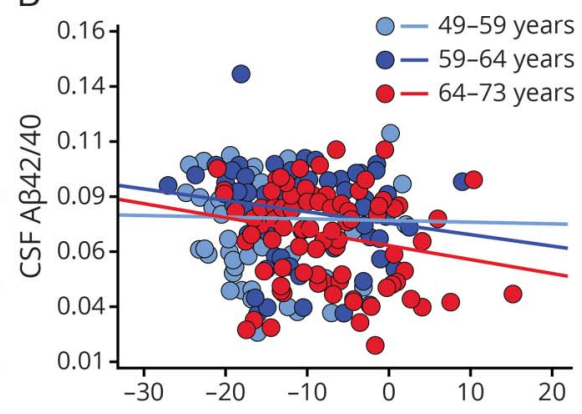

D

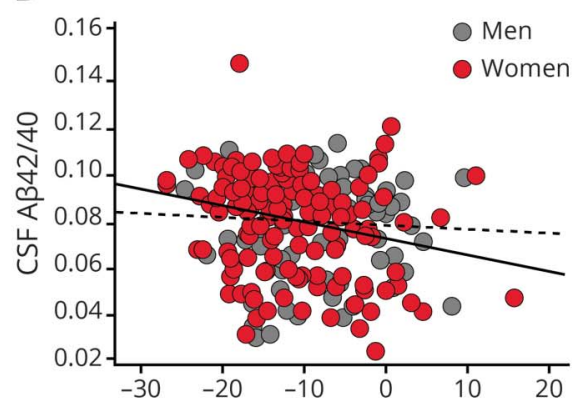

$\mathrm{F}$

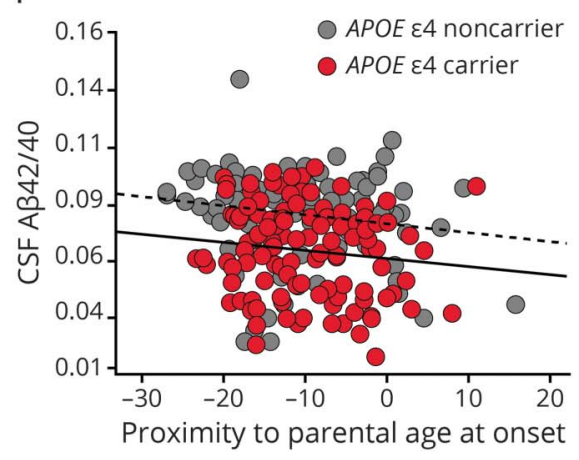

(A and B) Association between proximity to parental age at onset (AAO) and PET and CSF amyloid measurements, ( $C$ and $D$ ) interaction with sex, and ( $E$ and $F$ ) the nonsignificant interaction with $A P O E \& 4$ status. $A \beta=\beta$-amyloid; SUVR = standardized uptake value ratio.
When 2-way interactions were considered in the model, the interaction between proximity to parental AAO and age showed only trends toward significance. Age, sex, and years of education did not show any main effects or interactions with proximity to parental AAO (table 3 ).

In follow-up analyses, APOE\&4 status $(\beta=-0.016, p<0.001)$ and $\mathrm{FH}$ load ( 1 or 2 parents affected, $\beta=-0.015, p=0.004$ ) showed significant effects.

We also tested for quadratic relationships between proximity to parental AAO and amyloid biomarkers. The associations were not significant (data not shown).

In both amyloid PET and CSF models, the inclusion of proximity to parental AAO to a model already including age (sex and education) improved the explained variance with a borderline significance. The further inclusion of the interactions terms (proximity to parental AAO $\times$ age, proximity to parental AAO $\times$ sex, proximity to parental AAO $\times$ education) yielded a significant improvement in the model. Statistical details are provided in supplemental tables e 2 and e3, $10.5061 /$ dryad.280gb5mn1. Our data suggested that a model including age, sex, education, $A P O E \varepsilon 4$, and $\mathrm{FH}$ variables (PPAO, FH load, and interactions) significantly improved the variance explained on amyloid measurements by up to $8 \%$ compared to a model including age, sex, education, and $A P O E \& 4$ only (PET: model $R^{2}=0.14$ vs $R^{2}=0.21, R^{2}$ change $=0.08, F$ change $=4.91, p<0.001$; CSF: model $R^{2}=$ 0.21 vs $R^{2}=0.25, R^{2}$ change $=0.05, F$ change $=3.33, \mathrm{p}<$ $0.001)$. Statistical details are provided in supplemental tables e4 and e5, 10.5061/dryad.280gb5mn1.

No significant effects (or trends) of proximity to parental AAO were found in the model including phosphorylated tau as a dependent variable. However, there was a trend toward a 
Table 2 Results from the multiple regression analyses with flutemetamol-PET SUVR as the dependent variable

\begin{tabular}{lllrr}
\hline & $\beta$ Value & $95 \% \mathrm{Cl}$ & $\boldsymbol{t}$ Statistic & $\boldsymbol{p}$ Value \\
\hline Proximity to parental AAO & -0.064 & -0.105 to -0.023 & -3.01 & 0.002 \\
\hline Age & 0.018 & 0.01 to 0.03 & 4.56 & 0.001 \\
\hline Sex & 0.082 & 0.02 to 0.14 & -0.20 & 0.010 \\
\hline Years of education & -0.001 & -0.01 to 0.008 & 3.10 & 0.871 \\
\hline PPAAO $\times$ age & 0.001 & 0.0003 to 0.001 & 2.54 & 0.002 \\
\hline PPAAO $\times$ sex & 0.006 & 0.002 to 0.012 & 0.57 \\
\hline PPAAO $\times$ years of education & -0.0002 & -0.001 to 0.001 & 0.568 \\
\hline
\end{tabular}

Abbreviations: $\mathrm{Cl}$ = confidence interval; PPAAO = proximity to parental age at symptom onset.

The unstandardized $\beta$ represents the variation in flutemetamol-PET SUVRs with 1-unit variation in the independent variable.

significant association with age $(\beta=0.48, p<0.001)$. There were no further significant interactions.

\section{Associations between proximity to parental AAO and biomarkers of neural integrity}

Neural injury biomarkers models (including total tau or hippocampal volumes as dependent variables) testing for main effects did not show any significant association with proximity to parental AAO (total tau: $\beta=-0.878, p=0.172$; hippocampal volumes: $\beta=0.001, p=0.87$ ) but showed associations with age (total tau: $\beta=4.167, p<0.001$; hippocampal volumes: $\beta=$ $-0.37, p=0.008$ ). Sex and education were not significant (total tau: $\beta=6.439, p=0.467$, and $\beta=-0.367, p=756$; hippocampal volumes: $\beta=-0.145, p=0.239$, and $\beta=0.030, p=0.075$ ). When the interactions terms were included, no significant interaction was found between proximity to parental $\mathrm{AAO}$ and age (total tau: $\beta=-0.036, p=0.783$; hippocampal volumes: $\beta=$ $-0.002, p=0.433$ ) or education (total tau: $\beta=0.150, p=0.385$; hippocampal volumes: $\beta=-0.003, p=0.281)$. Furthermore, there was a borderline interaction between proximity to parental AAO and sex on total tau $(\beta=2.42, p=0.052)$ but not on hippocampal volumes $(\beta=-0.005, p=0.763)$.

\section{Associations of mental and vascular health with $A D$ and neural injury biomarkers}

We tested the effect modification of mental and vascular health on the significant relationships mentioned above by including the 2-way interactions between proximity to parental AAO and mental or vascular health. Because there were no associations between neural injury markers and proximity to parental $\mathrm{AAO}$ or $\mathrm{FH}$ variables, in neural injury models, we evaluated only whether vascular and mental health modified the associations with age. Sex and education were considered covariates in all the statistical models.

We did not find any effect modification of mental and vascular health on amyloid models. When hippocampal volume was the dependent variable in the model, no significant interaction of vascular health with age $(\beta=-0.002, p=0.23)$ was found. We found a significant interaction of mental health with age on hippocampal volumes $(\beta=-0.76, p=0.007)$ (figure 2 ). Because participants with history of anxiety and depression also showed higher scores on the HADS, we repeated the statistical models with the HADS score. However, no significant effect or interaction was found $(\beta=1.33, p=0.435)$. In

Table 3 Results from the multiple regression analyses with $A \beta_{40 / 42}$ ratio as the dependent variable

\begin{tabular}{|c|c|c|c|c|}
\hline & $\beta$ Value & $95 \% \mathrm{Cl}$ & t Statistic & $p$ Value \\
\hline PPAAO & 0.006 & 0.150 to 11.237 & 2.022 & 0.044 \\
\hline Age & -0.001 & -0.003 to -0.0004 & -2.826 & 0.005 \\
\hline Sex & -0.006 & -0.015 to -0.002 & -1.434 & 0.153 \\
\hline Years of education & -0.0001 & -0.001 to 0.001 & -0.276 & 0.783 \\
\hline PPAAO $\times$ age & -0.00008 & -0.0002 to -0.002 & -2.092 & 0.037 \\
\hline PPAAO $\times$ sex & -0.001 & -0.001 to 0.0002 & -1.515 & 0.131 \\
\hline PPAAO $\times$ years of education & -0.00001 & -0.0001 to 0.00008 & -0.292 & 0.711 \\
\hline
\end{tabular}

Abbreviations: $A \beta=\beta$-amyloid $C I=$ confidence interval; PPAAO = proximity to parental age at symptom onset

The unstandardized $\beta$ value represents the variation in $A \beta 4_{0 / 42}$ ratio with 1-unit variation in the independent variable. 
models including only main effects, the vascular health proxy showed a main effect on hippocampal volumes $(\beta=0.293, p=$ 0.015).

\section{Discussion}

The present study assesses $\mathrm{AD}$ and neural integrity biomarkers in $\mathrm{CU}$ middle-aged adults with $\mathrm{FH}$ of sporadic $\mathrm{AD}$. The main results of the study were that (1) proximity to parental AAO was linearly associated with amyloid burden as measured by PET and to a lesser extent with the $A \beta_{42 / 40}$ ratio, (2) the association was driven by participants in late midlife and women, (3) proximity to parental AAO, APOE\&4, and FH load independently contributed to amyloid burden, and (4) neural injury biomarkers did not change as a function of proximity to parental AAO but showed greater alterations with age in participants with lower mental health indicators.

Our findings suggest that middle-aged adults with $\mathrm{FH}$ of sporadic $\mathrm{AD}$ showed greater $\mathrm{A} \beta$ deposition as they approached parental age at symptom onset. Proximity to parental AAO was linearly associated with greater $A \beta$ deposition, notably during late midlife. Thus, both age and proximity to parental AAO contributed to explain the variability in $A \beta$ measurements. The results indicate that there are significant associations of age and $A \beta$ burden in middle-aged participants with $\mathrm{FH}$ of sporadic $\mathrm{AD}$ that are exacerbated as participants approach the age at symptom onset of the parents. The associations using the $A \beta_{42 / 40}$ ratio were similar but less statistically significant. While CSF $A \beta$ is thought to change earlier in the $\mathrm{AD}$ continuum, the nonlinear nature of the amyloid CSF measurement, together with the cross-

Figure 2 Plot showing the interaction of age and mental health on hippocampal volumes

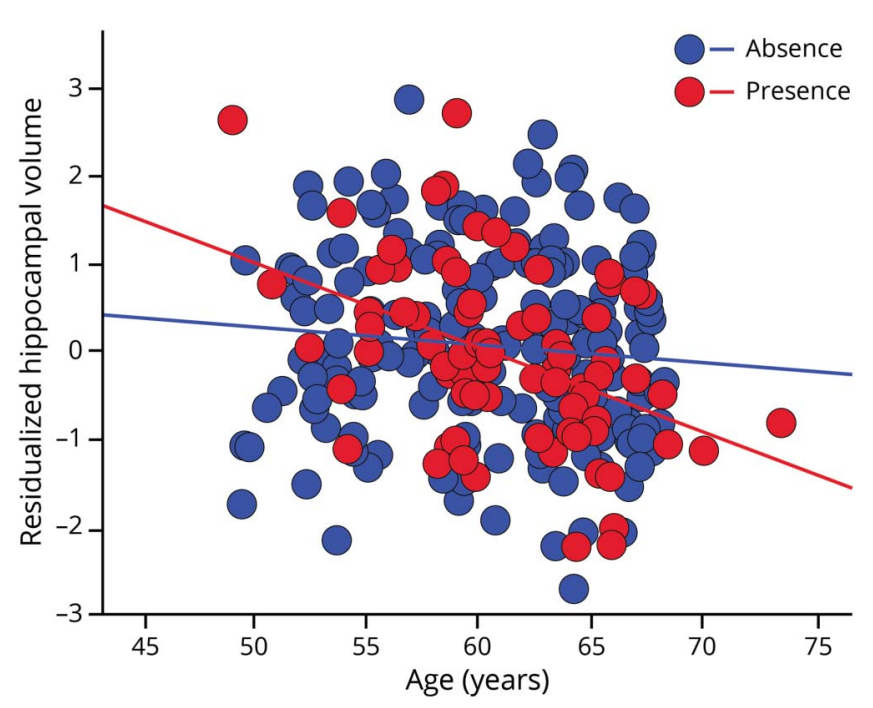

Presence refers to $>1$ mental health conditions (red) and absence none (dark blue). sectional design of the study, could have prevented us from detecting greater effects on CSF $A \beta$.

The present results reinforce findings from a previous study showing greater $A \beta$ burden as a function of proximity to parental AAO in 3 independent cohorts of middle-aged older adults. ${ }^{6}$ While the reported associations are moderate, together, the results support further research using this approach with longitudinal follow-up data and more powered statistical models. The inclusion of the proximity to parental AAO may help detect incipient or accelerated rates of $A \beta$ accumulation during midlife in risk-enriched populations. The success of clinical trials may depend partly on the ability to discriminate the earliest stages of $\mathrm{AD}$. Amyloid is accumulated over an $\approx 15$-year interval and follows a sigmoidal curve. ${ }^{23}$ Initial linear increases in individuals with overall low $\mathrm{A} \beta$ burden predict tau levels ${ }^{2}$ and cognitive decline. ${ }^{1}$ Therefore, detecting the earliest $A \beta$ changes is highly relevant. ${ }^{1}$ Future studies are guaranteed to assess whether the therapeutic window for preventive interventions starts earlier or is narrower in people with $\mathrm{FH}$ of sporadic $\mathrm{AD}$ dementia.

The variables of proximity to parental AAO, APOE $\varepsilon 4$ status, and $\mathrm{FH}$ load provided independent contributions to explain variability on amyloid-PET measurements. Proximity to parental AAO offers a continuous measure and thus a timeline for detection of incipient biomarker changes in risk-enriched population with $\mathrm{FH}$. We hypothesized that we would observe changes in neural injury biomarkers as proximity to parental $\mathrm{AAO}$ to a lesser extent than those observed with $\mathrm{AD}$ biomarkers. However, proximity to parental AAO, APOE\&4 status, and $\mathrm{FH}$ load were not significantly associated with greater alterations of phosphorylated tau or neural injury biomarkers (hippocampal volumes or total tau). Neural injury biomarkers showed only increases with age. Both APOE\&4 and the number of affected parents have been associated with amyloid load and to a lesser extent to neural injury biomarkers, notably hippocampal volumes. ${ }^{12,24}$ The results are in line with the idea that APOE\&4 and FH load act mainly through amyloiddependent pathways.

As previously reported, ${ }^{6}$ our findings support the usefulness of this approach in women. Indeed, only women showed increased $A \beta$ as they approached parental AAO. While the prevalence of $\mathrm{AD}$ is higher in women, whether women show earlier $\mathrm{AD}$ pathologic changes is a matter of debate. The sexspecific findings could be interpreted in different ways: because we focused on CU older adults, our results could reflect a survival bias in which only women close to the parental $\mathrm{AAO}$ and high $\mathrm{A} \beta$ burden remain $\mathrm{CU}$. Thus, women may be more resilient to $\mathrm{AD}$ pathologies. In line with this idea, men usually show more copathologies, ${ }^{25}$ which may lower brain resilience and result in a faster expression of cognitive impairment. Finally, under the assumption that proximity to parental AAO provides a disease timeline, our results may also imply that women show increased $A \beta$ deposition than men. However, previous studies in $\mathrm{CU}$ older adults did not show differences in 
$\mathrm{A} \beta$ burden between men and women. ${ }^{26}$ Although controversial reports exist, ${ }^{27}$ a meta-analysis showed no differences, ${ }^{4}$ and our data showed no main effect of sex.

The present study sample is a risk-enriched cohort (47\% APOE\&4 carriers) of middle-age older adults with $\mathrm{FH}$ of sporadic $\mathrm{AD}$ who thus are a candidate population for lifestyle interventions. The clinical expression of the disease may occur sooner in participants with risk-enhancing exposures and lower brain resilience and resistance to $\mathrm{AD}$ pathologies. ${ }^{10}$ Thus, we investigated the association of modifiable factors with $\mathrm{AD}$ and neural injury biomarkers to further understand factors that may increase resilience and resistance to $\mathrm{AD}{ }^{9}$ Recent research has shown that mental (e.g., stress, depression, and loneliness) and vascular health may be associated with $\mathrm{AD}$ pathologies and neural injury biomarkers. ${ }^{14,15}$ Education and early cognitive engagement have also been associated with $A \beta$ deposition. ${ }^{13,28}$ In this study, we did not find any factors associated with resistance to $A \beta$, the associations between education, mental and vascular health, and $A \beta$ burden were not significant. Furthermore, these factors did not modify the association of $A \beta$ with proximity to parental AAO. The effects of education and lifestyle factors on amyloid pathologies have been controversial across studies and may therefore be sample dependent. Nevertheless, we may not have been able to capture this effect due to the cross-sectional nature of the study. Therefore, this question deserves further assessment with longitudinal approaches.

Likewise, assessing the effects of modifiable factors on neural injury biomarkers on this population is of high relevance. Our results suggest that history of mental health was associated with exacerbated age effects on hippocampal volumes. Thus, middle-aged CU participants with a history of anxiety/depression showed lower hippocampal volumes with age. In complementary analyses, we showed that the history of anxiety/depression, rather than current anxiety/ depression levels, was associated with hippocampal volumes, suggesting that the cumulative effect of mental health conditions, rather than the current anxiety/depression levels, is more relevant. Previous studies suggest that mental health-related indicators may be early signs of the disease. ${ }^{14,15}$ However, our results support the idea that these factors increase $\mathrm{AD}$ dementia risk ${ }^{29,30}$ by lowering brain resilience.

The present study is not free of limitations. The effect sizes of the main measurements of interest were weak to moderate. However, we are investigating incipient pathology with a cross-sectional design; thus, strong effect sizes were not expected. While the sample size is relatively small, this is a well-characterized, risk-enriched sample derived from a large registry of participants with an extensive and careful assessment of FH. This allows a solid addition to previous research. Finally, proximity to parental AAO does not have the same implications as in autosomal-dominant $\mathrm{AD}^{31}$ because not all participants with $\mathrm{FH}$ of sporadic $\mathrm{AD}$ will develop dementia and some participants passed the parental AAO. Nevertheless, the present results together with previous findings ${ }^{6}$ support further research using this approach for the early detection of $\mathrm{A} \beta$ changes and risk-enrichment strategies.

In a risk-enriched sample of $\mathrm{CU}$ middle-aged participants with $\mathrm{FH}$ of sporadic $\mathrm{AD}$, proximity to parental $\mathrm{AAO}$ may offer a timeline for detection of incipient biomarker alterations, notably in women. Age-related effects on hippocampal volumes were exacerbated with worst mental health indicators. Mental health may thus be a candidate target for early interventions in $\mathrm{CU}$ adults with $\mathrm{FH}$ of $\mathrm{AD}$ and should be taken into account in the design of future trials.

\section{Acknowledgment}

This publication is part of the ALFA study. The authors express their sincere gratitude to the ALFA project participants, without whom this research would have not been possible. The authors thank Roche Diagnostics International Ltd. for kindly providing the kits for the CSF analysis of ALFA+ participants and GE Healthcare for kindly providing $[18 \mathrm{~F}]$ flutemetamol doses of ALFA+ participants.

\section{Study funding}

The research leading to these results has received funding from "la Caixa" Foundation (LCF/PR/GN17/10300004), the Alzheimer's Association, and an international anonymous charity foundation through the TriBEKa Imaging Platform project. Additional support has been received from the Universities and Research Secretariat, Ministry of Business and Knowledge of the Catalan Government under grant 2017-SGR-892. E.M.A.-U. is a recipient of an Alzheimer's Association research grant (AARG 2019-AARG-644641). E.M.A.-U. holds a "Ramón y Cajal" fellowship (RYC2018026053-I). J.D.G. holds a "Ramón y Cajal” fellowship (RYC2013-13054). M.S.-C. receives funding from the European Union's Horizon 2020 Research and Innovation Programme under the Marie Sklodowska-Curie action grant agreement 752310. C.M. was supported by the Spanish Ministry of Economy and Competitiveness (grant IEDI-2016-00690). K.B. holds the Torsten Söderberg Professorship in Medicine at the Royal Swedish Academy of Sciences and is supported by the Swedish Research Council (No. 2017-00915), the Swedish Alzheimer Foundation (No. AF-742881), Hjärnfonden, Sweden (No. FO2017-0243), and a grant (No. ALFGBG-715986) from the Swedish state under the agreement between the Swedish government and the county councils, the ALFagreement. H.Z. is a Wallenberg Academy Fellow supported by grants from the Swedish Research Council and the European Research Council. O.G.-R is supported by the Spanish Ministry of Economy, Industry and Competitiveness (FJCI-201733437).

\section{Disclosures}

E. Arenaza-Urquijo, G. Salvado, G. Operto, C. Minguillón, G. Sánchez-Benavides, M. Crous-Bou, O. Grau-Rivera, A. SalaVila, C. Falcón, and M. Suarez-Calvet report no disclosures 
relevant to the manuscript. $\mathrm{H}$. Zetterberg has served on scientific advisory boards for Samumed, CogRx, Wave, and Roche Diagnostics; has given lectures in symposia sponsored by Biogen and Alzecure; and is a cofounder of Brain Biomarker Solutions in Gothenburg AB, a GU Ventures-based platform company at the University of Gothenburg. K. Bennow has served as a consultant or on advisory boards for Abcam, Axon, Biogen, Lilly, MagQu, Novartis, and Roche Diagnostics and is a cofounder of Brain Biomarker Solutions in Gothenburg AB, a GU Venture-based platform company at the University of Gothenburg. J. Gispert reports no disclosures relevant to the manuscript. J. Molinuevo is a consultant for the following forprofit companies: Alergan, Roche Diagnostics, Genentech, Novartis, Lundbeck, Oryzon, Biogen, Lilly, Janssen, Green Valley, MSD, Eisai, Alector, Biocross, and Novo-nordisk. Go to Neurology.org/ $\mathrm{N}$ for full disclosures.

\section{Publication history}

Received by Neurology December 27, 2019. Accepted in final form May 8, 2020.

Appendix 1 Authors

\begin{tabular}{|c|c|c|}
\hline Name & Location & Contribution \\
\hline $\begin{array}{l}\text { Eider M. } \\
\text { Arenaza- } \\
\text { Urquijo, PhD }\end{array}$ & $\begin{array}{l}\text { Barcelonaßeta } \\
\text { Brain Research } \\
\text { Center, Spain }\end{array}$ & $\begin{array}{l}\text { Study concept and design, data } \\
\text { analysis and interpretation, } \\
\text { writing the manuscript }\end{array}$ \\
\hline $\begin{array}{l}\text { Gemma } \\
\text { Salvadó, MSc }\end{array}$ & $\begin{array}{l}\text { Barcelonaßeta } \\
\text { Brain Research } \\
\text { Center, Spain }\end{array}$ & Acquisition of data and analysis \\
\hline $\begin{array}{l}\text { Gregory } \\
\text { Operto, PhD }\end{array}$ & $\begin{array}{l}\text { Barcelonaßeta } \\
\text { Brain Research } \\
\text { Center, Spain }\end{array}$ & Acquisition of data and analysis \\
\hline $\begin{array}{l}\text { Carolina } \\
\text { Minguillón, } \\
\text { PhD }\end{array}$ & $\begin{array}{l}\text { Barcelonaßeta } \\
\text { Brain Research } \\
\text { Center, Spain }\end{array}$ & $\begin{array}{l}\text { Study design, critical revision of } \\
\text { the manuscript }\end{array}$ \\
\hline $\begin{array}{l}\text { Gonzalo } \\
\text { Sánchez- } \\
\text { Benavides, } \\
\text { PhD }\end{array}$ & $\begin{array}{l}\text { Barcelonaßeta } \\
\text { Brain Research } \\
\text { Center, Spain }\end{array}$ & $\begin{array}{l}\text { Data acquisition, interpretation, } \\
\text { critical revision of the } \\
\text { manuscript }\end{array}$ \\
\hline $\begin{array}{l}\text { Marta Crous- } \\
\text { Bou, PhD }\end{array}$ & $\begin{array}{l}\text { Barcelonaßeta } \\
\text { Brain Research } \\
\text { Center, Spain }\end{array}$ & $\begin{array}{l}\text { Interpretation, critical revision } \\
\text { of the manuscript }\end{array}$ \\
\hline $\begin{array}{l}\text { Oriol Grau- } \\
\text { Rivera, MD }\end{array}$ & $\begin{array}{l}\text { Barcelonaßeta } \\
\text { Brain Research } \\
\text { Center, Spain }\end{array}$ & $\begin{array}{l}\text { Data acquisition, interpretation, } \\
\text { critical revision of the } \\
\text { manuscript }\end{array}$ \\
\hline $\begin{array}{l}\text { Aleix Sala-Vila, } \\
\text { PhD }\end{array}$ & $\begin{array}{l}\text { Barcelonaßeta } \\
\text { Brain Research } \\
\text { Center, Spain }\end{array}$ & $\begin{array}{l}\text { Interpretation, critical revision } \\
\text { of the manuscript }\end{array}$ \\
\hline $\begin{array}{l}\text { Carles Falcón, } \\
\text { PhD }\end{array}$ & $\begin{array}{l}\text { Barcelonaßeta } \\
\text { Brain Research } \\
\text { Center, Spain }\end{array}$ & Acquisition and data analysis \\
\hline $\begin{array}{l}\text { Marc Suárez- } \\
\text { Calvet, MD }\end{array}$ & $\begin{array}{l}\text { Barcelonaßeta } \\
\text { Brain Research } \\
\text { Center, Spain }\end{array}$ & $\begin{array}{l}\text { Data acquisition, interpretation, } \\
\text { critical revision of the } \\
\text { manuscript }\end{array}$ \\
\hline $\begin{array}{l}\text { Henrik } \\
\text { Zetterberg, } \\
\text { MD }\end{array}$ & $\begin{array}{l}\text { University of } \\
\text { Gothenburg, } \\
\text { Sweden }\end{array}$ & $\begin{array}{l}\text { Interpretation, acquisition and } \\
\text { data analysis, critical revision of } \\
\text { the manuscript }\end{array}$ \\
\hline
\end{tabular}

Appendix 1 (continued)

\begin{tabular}{lll}
\hline Name & Location & Contribution \\
\hline $\begin{array}{l}\text { Kaj Blennow, } \\
\text { MD }\end{array}$ & $\begin{array}{l}\text { University of } \\
\text { Gothenburg, } \\
\text { Sweden }\end{array}$ & $\begin{array}{l}\text { Interpretation, acquisition and } \\
\text { data analysis, critical revision of } \\
\text { the manuscript }\end{array}$ \\
$\begin{array}{l}\text { Juan Domingo } \\
\text { Gispert, PhD }\end{array}$ & $\begin{array}{l}\text { Barcelonaßeta } \\
\text { Brain Research } \\
\text { Center, Spain }\end{array}$ & $\begin{array}{l}\text { Study design, interpretation, } \\
\text { critical revision of the } \\
\text { manuscript, study } \\
\text { supervision }\end{array}$ \\
\hline $\begin{array}{l}\text { José Luis } \\
\text { Molinuevo, }\end{array}$ & $\begin{array}{l}\text { Barcelonaßeta } \\
\text { Brain Research } \\
\text { Center, Spain }\end{array}$ & $\begin{array}{l}\text { Study design, interpretation, } \\
\text { critical revision of the } \\
\text { manuscript, study } \\
\text { supervision }\end{array}$ \\
\hline
\end{tabular}

Appendix 2 Coinvestigators

\begin{tabular}{|c|c|c|c|}
\hline Name & Location & Role & Contribution \\
\hline $\begin{array}{l}\text { Annabella } \\
\text { Beteta, MD }\end{array}$ & $\begin{array}{l}\text { Barcelonaßeta } \\
\text { Brain Research } \\
\text { Center, Spain }\end{array}$ & $\begin{array}{l}\text { Medical } \\
\text { Advisor }\end{array}$ & $\begin{array}{l}\text { Advised/reviewed the } \\
\text { clinical protocol, } \\
\text { performed clinical visits }\end{array}$ \\
\hline $\begin{array}{l}\text { Raffaele } \\
\text { Cacciaglia, } \\
\text { PhD }\end{array}$ & $\begin{array}{l}\text { Barcelonaßeta } \\
\text { Brain Research } \\
\text { Center, Spain }\end{array}$ & $\begin{array}{l}\text { Site } \\
\text { investigator }\end{array}$ & $\begin{array}{l}\text { Performed imaging } \\
\text { pipelines }\end{array}$ \\
\hline $\begin{array}{l}\text { Alba Cañas, } \\
\text { MSc }\end{array}$ & $\begin{array}{l}\text { Barcelonaßeta } \\
\text { Brain Research } \\
\text { Center, Spain }\end{array}$ & Neuropsychologist & $\begin{array}{l}\text { Performed } \\
\text { neuropsychological } \\
\text { evaluations }\end{array}$ \\
\hline $\begin{array}{l}\text { Carme } \\
\text { Deulofeu, } \\
\text { PhD }\end{array}$ & $\begin{array}{l}\text { Barcelonaßeta } \\
\text { Brain Research } \\
\text { Center, Spain }\end{array}$ & $\begin{array}{l}\text { Senior Clinical } \\
\text { Data Manager }\end{array}$ & $\begin{array}{l}\text { Coordinated and } \\
\text { supervised the data } \\
\text { systems and networks }\end{array}$ \\
\hline $\begin{array}{l}\text { Ruth } \\
\text { Dominguez, } \\
\text { MsC }\end{array}$ & $\begin{array}{l}\text { Barcelonaßeta } \\
\text { Brain Research } \\
\text { Center, Spain }\end{array}$ & $\begin{array}{l}\text { Clinical research } \\
\text { nurse }\end{array}$ & Performed clinical visits \\
\hline $\begin{array}{l}\text { Karine } \\
\text { Fauria, PhD }\end{array}$ & $\begin{array}{l}\text { Barcelonaßeta } \\
\text { Brain Research } \\
\text { Center, Spain }\end{array}$ & $\begin{array}{l}\text { Scientific } \\
\text { Manager }\end{array}$ & $\begin{array}{l}\text { Led the coordination of the } \\
\text { study, reviewed protocols }\end{array}$ \\
\hline $\begin{array}{l}\text { Maria } \\
\text { Pascual, MSc }\end{array}$ & $\begin{array}{l}\text { Barcelonaßeta } \\
\text { Brain Research } \\
\text { Center, Spain }\end{array}$ & Nurse & Performed clinical visits \\
\hline $\begin{array}{l}\text { José Maria } \\
\text { González-de- } \\
\text { Echavarri, } \\
\text { MD }\end{array}$ & $\begin{array}{l}\text { Barcelonaßeta } \\
\text { Brain Research } \\
\text { Center, Spain }\end{array}$ & Neurologist & $\begin{array}{l}\text { Performed clinical visits } \\
\text { and diagnostics }\end{array}$ \\
\hline $\begin{array}{l}\text { Xabier } \\
\text { Gotsens, } \\
\text { MSc }\end{array}$ & $\begin{array}{l}\text { Barcelonaßeta } \\
\text { Brain Research } \\
\text { Center, Spain }\end{array}$ & Neuropsychologist & $\begin{array}{l}\text { Performed } \\
\text { neuropsychological } \\
\text { evaluations }\end{array}$ \\
\hline $\begin{array}{l}\text { Laura } \\
\text { Hernandez, } \\
\text { MSc }\end{array}$ & $\begin{array}{l}\text { Barcelonaßeta } \\
\text { Brain Research } \\
\text { Center, Spain }\end{array}$ & $\begin{array}{l}\text { Clinical research } \\
\text { nurse }\end{array}$ & Performed clinical visits \\
\hline $\begin{array}{l}\text { Gema } \\
\text { Huesa, PhD }\end{array}$ & $\begin{array}{l}\text { Barcelonaßeta } \\
\text { Brain Research } \\
\text { Center, Spain }\end{array}$ & $\begin{array}{l}\text { Clinical data } \\
\text { manager }\end{array}$ & $\begin{array}{l}\text { Performed and } \\
\text { coordinated data entry, } \\
\text { storage, and } \\
\text { organization }\end{array}$ \\
\hline $\begin{array}{l}\text { Jordi } \\
\text { Huguet, MSc }\end{array}$ & $\begin{array}{l}\text { Barcelonaßeta } \\
\text { Brain Research } \\
\text { Center, Spain }\end{array}$ & $\begin{array}{l}\text { IT Neuroimaging } \\
\text { specialist }\end{array}$ & $\begin{array}{l}\text { Performed data entry, } \\
\text { storage, and organization, } \\
\text { performed imaging } \\
\text { pipelines }\end{array}$ \\
\hline $\begin{array}{l}\text { Paula } \\
\text { Marne, MSc }\end{array}$ & $\begin{array}{l}\text { Barcelonaßeta } \\
\text { Brain Research } \\
\text { Center, Spain }\end{array}$ & Neuropsychologist & Performed clinical visits \\
\hline $\begin{array}{l}\text { Tania } \\
\text { Menchón, } \\
\text { MSc }\end{array}$ & $\begin{array}{l}\text { Barcelonaßeta } \\
\text { Brain Research } \\
\text { Center, Spain }\end{array}$ & Nurse Coordinator & $\begin{array}{l}\text { Coordinated and } \\
\text { performed clinical visits }\end{array}$ \\
\hline
\end{tabular}

Continued 


\begin{tabular}{|c|c|c|c|}
\hline $\begin{array}{l}\text { Marta Milà- } \\
\text { Alomà, MSc }\end{array}$ & $\begin{array}{l}\text { Barcelonaßeta } \\
\text { Brain Research } \\
\text { Center, Spain }\end{array}$ & Site investigator & $\begin{array}{l}\text { Performed biostatistical } \\
\text { analyses }\end{array}$ \\
\hline $\begin{array}{l}\text { Albina Polo, } \\
\text { MD }\end{array}$ & $\begin{array}{l}\text { Barcelonaßeta } \\
\text { Brain Research } \\
\text { Center, Spain }\end{array}$ & Medical Advisor & $\begin{array}{l}\text { Advised/reviewed the } \\
\text { clinical protocol, } \\
\text { performed clinical visits }\end{array}$ \\
\hline $\begin{array}{l}\text { Sandra } \\
\text { Pradas, MSc }\end{array}$ & $\begin{array}{l}\text { Barcelonaßeta } \\
\text { Brain Research } \\
\text { Center, Spain }\end{array}$ & Nurse & Performed clinical visits \\
\hline $\begin{array}{l}\text { Anna } \\
\text { Soteras, MSc }\end{array}$ & $\begin{array}{l}\text { Barcelonaßeta } \\
\text { Brain Research } \\
\text { Center, Spain }\end{array}$ & $\begin{array}{l}\text { Clinical Study } \\
\text { Coordinator }\end{array}$ & Coordinated clinical visits \\
\hline $\begin{array}{l}\text { Marc } \\
\text { Vilanova, } \\
\text { BSc }\end{array}$ & $\begin{array}{l}\text { Barcelonaßeta } \\
\text { Brain Research } \\
\text { Center, Spain }\end{array}$ & MRI Technician & $\begin{array}{l}\text { Supervised and performed } \\
\text { MRI data acquisition }\end{array}$ \\
\hline $\begin{array}{l}\text { Natalia } \\
\text { Vilor- } \\
\text { Tejedor, PhD }\end{array}$ & $\begin{array}{l}\text { Barcelonaßeta } \\
\text { Brain Research } \\
\text { Center, Spain }\end{array}$ & Site investigator & $\begin{array}{l}\text { Performed biostatistical } \\
\text { analyses }\end{array}$ \\
\hline
\end{tabular}

\section{References}

1. Landau SM, Horng A, Jagust WJ; Alzheimer's Disease Neuroimaging Initiative. Memory decline accompanies subthreshold amyloid accumulation. Neurology 2018; 90:e1452-e1460.

2. Leal SL, Lockhart SN, Maass A, Bell RK, Jagust WJ. Subthreshold amyloid predicts tau deposition in aging. J Neurosci 2018;38:4482-4489.

3. Vemuri P. "Exceptional brain aging” without Alzheimer's disease: triggers, accelerators, and the net sum game. Alzheimers Res Ther 2018;10:53.

4. Jansen WJ, Ossenkoppele R, Knol DL, et al. Prevalence of cerebral amyloid pathology in persons without dementia: a meta-analysis. JAMA 2015;313: 1924-1938.

5. Mosconi L, Rinne JO, Tsui WH, et al. Increased fibrillar amyloid-\{beta $\}$ burden in normal individuals with a family history of late-onset Alzheimer's. Proc Natl Acad Sci USA 2010;107:5949-5954.

6. Villeneuve S, Vogel JW, Gonneaud J, et al. Proximity to parental symptom onset and amyloid- $\beta$ burden in sporadic Alzheimer disease. JAMA Neurol 2018;75:608-619.

7. Vemuri P, Knopman DS, Lesnick TG, et al. Evaluation of amyloid protective factors and Alzheimer disease neurodegeneration protective factors in elderly individuals. JAMA Neurol 2017;74:718-726.

8. Okonkwo OC, Schultz SA, Oh JM, et al. Physical activity attenuates age-related biomarker alterations in preclinical AD. Neurology 2014;83:1753-1760.

9. Walters MJ, Sterling J, Quinn C, et al. Associations of lifestyle and vascular risk factors with Alzheimer's brain biomarker changes during middle age: a 3-year longitudinal study in the broader New York City area. BMJ Open 2018;8:e023664.

10. Arenaza-Urquijo EM, Vemuri P. Resistance vs resilience to Alzheimer disease: clarifying terminology for preclinical studies. Neurology 2018;90:695-703.

11. Buckley RF, Mormino EC, Rabin JS, et al. Sex differences in the association of global amyloid and regional tau deposition measured by positron emission tomography in clinically normal older adults. JAMA Neurol 2019;76:542-551.
12. Mosconi L, Murray J, Tsui WH, et al. Brain imaging of cognitively normal individuals with 2 parents affected by late-onset AD. Neurology 2014;82:752-760.

13. Arenaza-Urquijo EM, Bejanin A, Gonneaud J, et al. Association between educational attainment and amyloid deposition across the spectrum from normal cognition to dementia: neuroimaging evidence for protection and compensation. Neurobiol Aging 2017;59:72-79.

14. Donovan NJ, Okereke OI, Vannini P, et al. Association of higher cortical amyloid burden with loneliness in cognitively normal older adults. JAMA Psychiatry 2016;73: 1230-1237.

15. Donovan NJ, Locascio JJ, Marshall GA, et al. Longitudinal association of amyloid- $\beta$ and anxious-depressive symptoms in cognitively normal older adults. Am J Psychiatry 2018;175:530-537.

16. Gatchel JR, Donovan NJ, Locascio JJ, et al. Depressive symptoms and tau accumulation in the inferior temporal lobe and entorhinal cortex in cognitively normal older adults: a pilot study. J Alzheimers Dis 2017;59:975-985.

17. Vemuri P, Lesnick TG, Knopman DS, et al. Amyloid, vascular, and resilience pathways associated with cognitive aging [online]. J Alzheimers Dis Accessed at: onlinelibrary. wiley.com/doi/abs/10.1002/ana.25600. Accessed November 5, 2019

18. Molinuevo JL, Gramunt N, Gispert JD, et al. The ALFA project: a research platform to identify early pathophysiological features of Alzheimer's disease. Alzheimers Dement 2016;2:82-92.

19. Bittner T, Zetterberg $\mathrm{H}$, Teunissen $\mathrm{CE}$, et al. Technical performance of a novel, fully automated electrochemiluminescence immunoassay for the quantitation of $\beta$-amyloid (1-42) in human cerebrospinal fluid. Alzheimers Dement 2016;12:517-526.

20. Quintana JM, Padierna A, Esteban C, Arostegui I, Bilbao A, Ruiz I. Evaluation of the psychometric characteristics of the Spanish version of the Hospital Anxiety and Depression Scale. Acta Psychiatr Scand 2003;107:216-221.

21. Jack CR, Wiste HJ, Weigand SD, et al. Different definitions of neurodegeneration produce similar amyloid/neurodegeneration biomarker group findings. Brain 2015; 138:3747-3759.

22. Salvadó G, Molinuevo JL, Brugulat-Serrat A, et al. Centiloid cut-off values for optimal agreement between PET and CSF core AD biomarkers. Alzheimers Res Ther 2019; $11: 27$.

23. Jack CR Jr, Wiste HJ, Lesnick TG, et al. Brain $\beta$-amyloid load approaches a plateau. Neurology 2013;80:890-896

24. Fouquet M, Besson FL, Gonneaud J, La Joie R, Chételat G. Imaging brain effects of APOE4 in cognitively normal individuals across the lifespan. Neuropsychol Rev 2014 24:290-299.

25. Gambassi G, Lapane KL, Landi F, Sgadari A, Mor V, Bernabie R. Gender differences in the relation between comorbidity and mortality of patients with Alzheimer's disease: Systematic Assessment of Geriatric drug use via Epidemiology (SAGE) Study Group. Neurology 1999;53:508-516.

26. Jack CR, Therneau TM, Weigand SD, et al. Prevalence of biologically vs clinically defined Alzheimer spectrum entities using the National Institute on Aging-Alzheimer's Association research framework. JAMA Neurol 2019;76:1174-1183.

27. Scheinin NM, Wikman $\mathrm{K}$, Jula A, et al. Cortical ${ }^{11} \mathrm{C}-\mathrm{PIB}$ uptake is associated with age, APOE genotype, and gender in "healthy aging.". J Alzheimers Dis 2014;41:193-202.

28. Landau SM, Marks SM, Mormino EC, et al. Association of lifetime cognitive en gagement and low $\beta$-amyloid deposition. Arch Neurol 2012;69:623-629.

29. Marchant NL, Howard RJ. Cognitive debt and Alzheimer's disease. J Alzheimers Dis 2015;44:755-770.

30. Gimson A, Schlosser M, Huntley JD, Marchant NL. Support for midlife anxiety diagnosis as an independent risk factor for dementia: a systematic review. BMJ Open 2018;8:e19399.

31. Bateman RJ, Xiong C, Benzinger TLS, et al. Clinical and biomarker changes in dominantly inherited Alzheimer's disease. N Engl J Med 2012;367:795-804 


\section{Neurology}

\section{Association of years to parent's sporadic onset and risk factors with neural integrity and Alzheimer biomarkers \\ Eider M. Arenaza-Urquijo, Gemma Salvadó, Gregory Operto, et al. \\ Neurology 2020;95;e2065-e2074 Published Online before print July 31, 2020}

DOI 10.1212/WNL.0000000000010527

This information is current as of July 31, 2020

\section{Updated Information \&} Services

References

Citations

Subspecialty Collections

Permissions \& Licensing

Reprints including high resolution figures, can be found at: http://n.neurology.org/content/95/15/e2065.full

This article cites 30 articles, 10 of which you can access for free at: http://n.neurology.org/content/95/15/e2065.full\#ref-list-1

This article has been cited by 1 HighWire-hosted articles: http://n.neurology.org/content/95/15/e2065.full\#\#otherarticles

This article, along with others on similar topics, appears in the following collection(s):

\section{Alzheimer's disease}

http://n.neurology.org/cgi/collection/alzheimers_disease

\section{MRI}

http://n.neurology.org/cgi/collection/mri

PET

http://n.neurology.org/cgi/collection/pet

Information about reproducing this article in parts (figures,tables) or in its entirety can be found online at:

http://www.neurology.org/about/about_the_journal\#permissions

Information about ordering reprints can be found online:

http://n.neurology.org/subscribers/advertise

Neurology ${ }^{\circledR}$ is the official journal of the American Academy of Neurology. Published continuously since 1951, it is now a weekly with 48 issues per year. Copyright () 2020 American Academy of Neurology. All rights reserved. Print ISSN: 0028-3878. Online ISSN: 1526-632X.

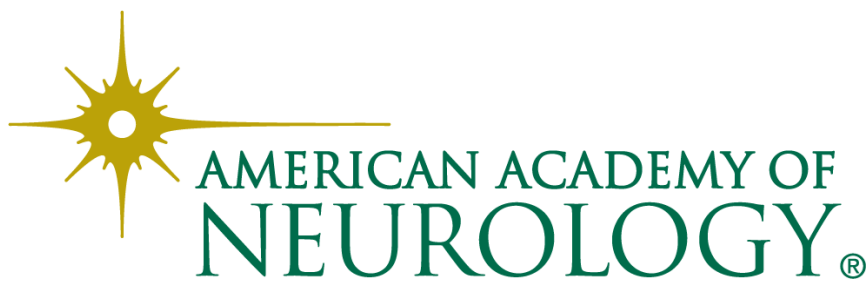

